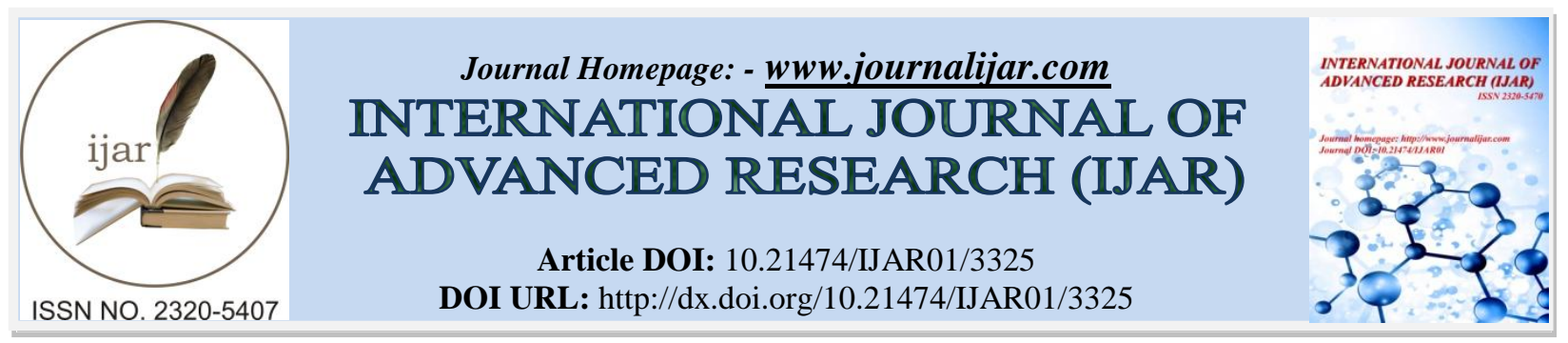

RESEARCH ARTICLE

\title{
EFFECTS OF OUTSOURCING ON ORGANIZATIONAL PERFORMANCE IN KENYA.
}

\author{
Maurice M. Opiyo. \\ Rongo University, P.O. Box 103-40404, Rongo, Kenya.
}

\section{Manuscript Info}

Manuscript History

Received: 22 December 2016

Final Accepted: 10 January 2017

Published: February 2017

Key words:-

Outsourcing, organizational

performance, effects, Kenya

\begin{abstract}
The purpose of this study was to determine the effects of outsourcing on an organizational performance. Performance refers to how well or badly an individual or institution is doing in achieving its designated tasks (Ashby 2002). Managers want their organizations to achieve high levels of performance, no matter what mission, strategies, or goals are being pursued. Other specific objectives include productivity, costs and quality. It was established how productivity, costs and quality affect the performance of an organization. The review's findings established that outsourcing in the organization was not fully effective. It also showed that outsourcing had effects on productivity, costs and quality of goods and services produced thus subsequently affecting the performance of K.I.A (Kenya Institute of Administration) for instance. Bulk buying, procurement of approved goods and services, hiring qualified personnel and evaluation of the process to identify the best line of fit and identification of the best brand in the market, and checks to ensure goods and services procured are recommended.
\end{abstract}

Copy Right, IJAR, 2017,. All rights reserved.

\section{Introduction:-}

Heshmati (2003) in his survey points out that there is no general definition or measurement of outsourcing, he broadly describes it as a different kind of corporate action related to all subcontracting relationships between firms and the hiring of workers in a non-traditional jobs. Outsourcing may provide a viable strategy if firms aim to save on labour costs (Abraham and Tailor, 1996), exploit production differentials both within the services sectors and between services and manufacturing (Fixler and Siegel 1999), or take advantage of Globalization (Freenstra and Hanson, 1999).

Outsourcing is a strategic management tool that involve contracting of a company's non-core, non-revenue generating activities to a third party, commonly referred to as service provider. The process of outsourcing entails a long relationship between the supplier and the beneficiary, with a high degree of risk sharing (Corbett, 2004). The essence of outsourcing is to look for expertise to handle certain business functions outside the existing firm. The decision making process that management must undergo when considering outsourcing hinges on a "make or buy" philosophy. Outsourcing emerged from the moribund economy of the 1980s and 1990s, with emphasis on cutting costs driving the primary focus of successful firms. The renewed focus on outsourcing has mainly been driven by changes in information technology, communication and reengineering organizations (Embelton and Wright1998).

An organization's performance goals can only be achieved through its employees. An effective performance measurement and management system links individual and team work behavior to the organization's business 
strategies, goals, and values. For achievement of its goals, it is essential for each employee to understand individual roles and responsibilities for goal achievement and there must be continuous dialogue between leaders and employees to set performance expectations, measure and analyze, and manage performance-three essential action steps that are interlinked and an ongoing in an organizational culture that successfully measures and account for performance. During the performance planning phase, the first phase of performance measurement, the organizational business strategy-including its mission, vision and objectives, and specific outcome required to achieve the overall strategy is defined. Goals and plans on how to measure achievement must be identified. In this step, outputs and measures are identified and requisite data collection and analysis process and procedure are developed and implemented.

Additionally, employees come to understand their individual roles and responsibilities with respect to performance measurement and are given the fundamental information, resources, competencies and motivation to ensure their successful execution. In the second phase measurement process-the measurement and analysis phase-data that informs areas of success and challenge for the organization are collected and are analyzed. Specific elements and factors that contributes success or challenge along with new/or modified information needs and lessons learned are identified. Once the performance data has been collected and analyzed, it must be effectively managed. The third phase of the process-performance management-is the phase in which solutions to address the identified challenges are developed and implemented, along with mechanisms to ensure the continuation of programme or organizational success. Additionally, performance measurement system and process may be modified as need to ensure that information collected through the performance measurement process is timely, relevant, and sufficient-steps that cycle back to performance planning (Poster, 2003).

Further, Smith (2000) asserted that most corporations believe that in order to compete globally and efficiently, cost must be rather than relying strictly on revenue growth. Therefore, organizations around the world are increasingly considering outsourcing as a strategic measurement tool which can be leveraged to allow focusing on their core competencies.

Heartman and Bengtsson (2007) point out that Business Process Outsourcing (BPO) gives tremendous help to companies to concentrate on the core areas of business. The most important factor in the growth of the BPO market worldwide today, is an increase in the number of enterprises that are reviewing their internal operations is an attempt to fully understand their true competencies. In this process companies are able to focus more on their core competencies to improve performance. Elmuti (2003) finally adds that those companies that are successful in outsourcing share the same success factors. These factors include clear understanding of their core activities, conducting adequate research and planning, and most importantly have developed clear objectives, goals and expectations of outsourcing activities. It is also essential that the right partners are selected based on a criteria like credibility, expertise and reliability.

A fundamental question to ask is whether outsourcing is value enhancing and, in particular, whether the firm that undertakes outsourcing shows higher profitability as a result. Essentially, this question renders down to the transactions cost question regularly posed to university undergraduates: should a firm manufacture its own input by some form of vertical merger or should it seek to obtain possibly more competitively priced inputs on the open market? While the viability of vertical mergers as determinant of profitability is comparatively well researched, less work has been undertaken on the viability of pursuing a less integrated strategy, namely of outsourcing inputs (Bhuyan, 2002).

Njihia (2005) affirmed that performance is an action or achievement considered in relation to how successful it is. It is the ability to operate effectively or to react quickly. Amstrong (2006) stated that performance is often defined simply in output terms-the achievement of qualified objectives. But performance is a matter of not only how people achieve, but how they achieve it. Performance means both behavior and results. Behaviors emulate from that performer and transform performance from abstraction to action. Not just the instruments for results, behaviors are also outcomes in their own right-the product of mental and physical effort applied to tasks and can be judged apart from results.

Outsourcing is subcontracting, a process such as product design or manufacturing, to a third party company. The decision to outsource is often made in the interest of lowering costs or making better use of time and energy costs, redirecting or conserving energy directed at the competencies of a particular business, or to make efficient use of 
land, labour, capital, (information) technology and resources. It became part of the business lexicon in the 1980s. It is essentially a division of labour. It involves the transfer of management of day to day execution of an entire business function to an external service provider. The client organization and the supplier enter a contractual agreement that defines the transferred services. Under the agreement, the supplier acquires the means of production in the form of transfer of people, assets and other resources from the client. The client agrees to procure the services from the supplier for the term of the contract; business segments typically outsourced include information technology, human resources, facilities, real estate management and accounting (Oversby 2007)

Organizational performance is used in three time-senses-the past, present and the future, in other words, performance can refer to something completed or something happening now, or activities that prepare for new needs. Profitability, for example, is often regarded as the ultimate performance indicator, but it is not the actual performance. The actual performance occurred time back-first with decisions and then the actions that followed the decisions. Profit is therefore an indicator of previous performance. In this sense, performance is the outcome or 'end'.

There are behaviors that are associated with good or high performance, and then one must identify and assess them as they occur. These behaviors start with strategic planning process and continue into implementation, monitoring and assessment. In this sense, performance is the 'activity' or 'means' organizations are also interested in the predictors of performance-conditions and behaviors that have been shown over time to lead to better performance. In this sense, performance is a package of behaviors around strategic planning and programming (www.strategicconversation.com.au)

Robert S. Kaplan and David P. Norton (1992) introduced the balanced score card, a set of measures that allow for a holistic, integrated view of business performance. The scorecard was originally created to supplement "traditional financial measures with criteria that measured performance from three additional perspectives-those of customers, internal business processes, learning and growth (Kaplan and Norton, 1996,p. 75). By 1996, user companies had further developed it as a strategic management system linking long term strategy to short term targets. The development of the balanced scorecard method occurred because many business organizations realized that focus on one dimensional measure of performance (such as returns on investment or increased profit) was inadequate.

Too often bad strategic decisions were made in an effort to increase the bottom line at the expense of other organizational goals. The theory of the balanced scorecard suggested that rather than the focus, financial performance is the natural outcome of balancing other important goals. These other organizational goals interact to support excellent overall organizational preferences. If any individual goal is out of balance with other goals, the performance of the organization as a whole will suffer. The balanced scorecard system also emphasizes articulation of strategic targets in support of goals. In addition measurement systems are developed to provide data necessary to know when targets are being achieved or when performance is out of balance or being negatively affected. The Kaplan and Norton balanced scorecard looks at a performance refers to how well or badly an individual or institutions doing in achieving its designated tasks (Ashby, 2002). It may also be described as the end result of an activity but for an organization this would refer to how well it's achieving its mission, goals and objectives. It is the accumulated end result of all the organization's work processes and activities. Managers want their organization to achieve high levels of performance; no matter what mission, goals or strategies are being pursued. The first importance of measuring organizational performance is better asset management which refers to the process of acquiring, managing, renewing and disposing of assets as needed and of designing business models to exploit the value from the assets.

The second importance is of the increased ability to provide customer value. Customers will look elsewhere if they are not receiving value from an organization. Managers should therefore monitor how well they are providing customer value and they can do that when they measure performance. The third importance is on the impact on organizational reputation. Organizations strive to have a good reputation reflected to their customers, suppliers, competitors, community and others. The final importance is improved measures of organizational. Modern organizations must be able to learn and respond quickly i.e. they must be learning organizations. Organizational knowledge is that created by collaborative information sharing and social interaction that lead the organization members taking appropriate actions thus considered an asset (Robbins and Courtler, 2003). 
The most frequent measures of organizational performance include organizational productivity, organizational effectiveness and industry rankings. Kaplan and Norton (1997) assert that productivity is an economic term that means output created in terms of goods and services produced rendered per resource unit. It is the overall output of goods or services divided by the inputs to generate that output. Robbins and Coutler (2003) add that organizational effectiveness as the measure of how appropriate organizations are in achieving their goals.

While outsourcing of services has received a lot of attention in the media and political circles in recent years largely because media reports seem to equate outsourcing with job losses (Wei and Amiti, 2004) or creation of jobs (Russel, 2007), this concept has made its accessibility to many organizations on a national and international level. Offshore outsourcing has provided many businesses with the opportunity to harvest the benefits of lowering labour costs in developing countries (Frayer et al., 2000) and also exploiting the value of artificially manipulated foreign currencies, where the exchange rate is undervalued. Counties that have benefited on these outsourced programs include India, china and Latin America. According to Russell (2007), almost every organization applies the outsourcing concept in some way.

Typically, the function being outsource is considered non-core to the business. However, there exists instance where organizations have outsourced their core business (Bengtsson and Haartman, 2007). These authors have reported that in their studies about 50\% of engineering companies outsourced manufacturing, a process that is viewed as a core business. This study also reported that outsourcing is more common among larger companies than smaller ones. Embelton and Wright (1998) add that large organizations are doing more extensive outsourcing than small to medium size firms especially for maintenance and repairs outsourcing MRO. The study also indicated that manufacturing organizations seem to do less outsourcing than other commercial enterprises. In this study, $80 \%$ of the firms doing substantial and extensive outsourcing of MRO had revenues of over $\$ 5$ billion. For strategic items, only $15 \%$ of the companies reported moderate to extensive outsourcing activity. More than half of this group is composed of companies with $\$ 5$ billion or more in annual revenue.

Outsourcing entered the business lexicon in 1980s since then many organizations have embraced this concept with major interest if reducing costs and also focusing on the core competencies which would contribute greatly to performance of their companies. According to Automated Data Processing (2007), 100\% of Canadian executives surveyed agreed that outsourcing allows their companies to focus on their core competencies, $89 \%$ of these respondents also identified payroll as the best candidate for business process outsourcing in an endeavor to reduce costs.

In Kenya, the organizations that have adopted the concept of reengineering of their process have mainly done so in an effort to reduce costs. In an interview with some key players in the manufacturing process in Nairobi (March 2007), they asserted that outsourcing of processes had greatly contributed to the good performance of their organizations. This achievement was mainly attributed to cost reduction, enhanced focus on core business and increased flexibility and efficiency of their process, this confirms their reports in literature (Elmuti, 2003).

According to Johnson \& Scholes (2007), many managers find the process of developing a useful set of performance indicators for their organizations difficult. One reason for this is that many indicators give only a useful but partial view of the overall picture. Also some indicators are qualitative in nature, whilst the hard quantitative end of assessing performance has been dominated by financial analysis. In an attempt to cope with this very heterogeneous situation, balanced scorecards have been used as a way of identifying useful but varied set of measures. Balanced scorecards combine both qualitative and quantitative measures, acknowledge the expectations of different stakeholders and relate an assessment of performance of different stakeholders and relate an assessment of performance to choice of strategy.Currently, outsourcing has taken many forms (Russell, 2007; Kakabadse and Kakabadse, 2002).

In Literature, the most common forms are information technology outsourcing (ITO) and business process outsourcing (BPO). Business process outsourcing encompasses call centre outsourcing, human outsourcing. These outsourcing deals involve multi-layer contact that can run into billions of dollars (Russell, 2007). Outsourcing is the practice of using outside firms to handle work done within a company and is a familiar concept to many entrepreneurs. Small companies routinely outsource their payroll processing, accounting, distribution and many other important functions often because they have no other choice. Many large companies turn to outsourcing to cut costs. In response, entire industries have evolved to serve companies outsourcing needs. But not many businesses 
thoroughly understand the benefits of outsourcing. It is true that outsourcing can save money, buts that are not the only reason to do it. As many firms discovered during the outsourcing mania of the early 1990s, outsourcing too much can even be a bigger mistake than not outsourcing any work at all. This creates the need to understand it well as to apply it. (www.allbusiness.com).

\section{Effects of Outsourcing on Performance:- Increased productivity:-}

Smith (2000) noted that organizations around the world are continuously considering outsourcing as a strategic management tool which can be leveraged to allow them to focus on their core competencies. Non-core processes should be outsourced allowing the organization to realize financial and competitive advantages by reallocating internal resources to focus on core competencies. Okafor (2005) established that the practice of outsourcing began simply as a cost cutting techniques and developed to a core strategic activity aimed at enabling companies focus on their core business. This concentration on the core competencies leads to improved efficiencies and productivity. Elmuti, (2003) affirmed that traditional outsourcing emphasizes on tactical benefits like cost reduction but this has recently been replaced by productivity, flexibility, speed and innovation in developing business applications and access to new technologies and skills. Once an outsourcing of certain processes takes place, it becomes easier for the company to compare and evaluate the efficiency and effectiveness of services that are being delivered from outside to inside. This trend is leading to an increased keenness to outsourcing process that are considered non-core yet critical activities.

Russel, (2003) outlined that it is now clear for many outsourcing companies that what began 25 years ago as a cost cutting measure has evolved into an important way of achieving efficiency with the organizations. Over the years, there has been a change in the type of work that is being outsourced by firms. There has been a shift from single clerical type of work to more skilled, professional type of services. Several firms have developed different methods of achieving efficiency and productivity. Though what stands more are the generally accepted world class process improvement system that are widely acceptable. Most of these process improvement employed by organizations are aimed at improving efficiency and productivity. This is because these systems eliminate defects: resolve respective quality and productivity issues. The first efforts of improving quality are usually on improving their process and hence productivity (Brecker Associates, 2007)

In Kenya Microsoft reported company growth due to the outsourcing of noncore services. This was through working with local service providers who gave it better control of its processes by working closely with companies within reach. This created local partnership and built efficiency. Despite the growing significance of outsourcing, there is a limited understanding of performance outcome of the firms that engage in outsourcing. Literature is abounding with contradictory information on the effect of outsourcing on the efficiency and productivity of the process. These differences are varied as the many types of operations (The Standard, May 16, 2007)

\section{Costs/value addition:-}

Russell (2007) pointed out that even when a business attempts to improve customer services or increase quality; it does so within the framework of cost reduction. In most professional Organizations typically have $10 \%$ or more profit opportunity hidden in their business that can be achieved through reduction of costs. These hidden profits can be trapped through outsourcing as a strategic tool in most organizations.

Ellram (1997) asserts that outsourcing not only impart an organization with the best practices, but also brings about greater level of integration among processes and technology. Good outsourcing drive high level of efficiency, hence improved profits.

When choosing suppliers or venders, sourcing managers must compare options based on the supplier's impact on the total cost of ownership (TCO). Several other factors besides purchase price are included in TCO analysis. They may include: replenishment lead time, on-time performance, supply flexibility, delivery frequency, supply quality, inbound transportation cost, pricing terms, information coordination capability, design collaboration capability, exchange rates, taxes and supplier viability. There is a three step process to evaluate supplier using the total cost of ownership concept: Identify all activities to be captured in TCO, qualify cost drivers using activity-based costing and calculating the TCO of each supplier (Chopra and Meindl, 2007). 
In many firms the understanding of concept of outsourcing stops at the process of cost cutting. Indeed, shareholders are still putting pressure on managers to cut costs. This pressure to cut costs and reorganize has been felt most strongly in vertically integrated companies. While the internal importance of these efforts has been evident, cost reduction is gaining increasingly more attention from companies as well. In addition, consultants and companies frequently use cost saving figures when discussing the success of the latest business initiative, including strategic sourcing. Outsourcing is not only based on cost advantage but also viewed as an integral part of creation of sustainable competitive advantage in today's business should possess a competitive advantage in order to compete effectively in the market place (Corbett, 2004).

\section{Quality improvement:-}

Elmuti (2003) reported that quality improvement was one of the top reasons why organizations undertake outsourcing projects. This supports previous findings (Quinn, 2000) that outsourcing was undertaken for purposes that have impact on the organization's bottom line, quality and other reasons. Corbett (2004) adds that poor quality of products and services are accepted by consumers because accountability systems regarding consumer or user feedback are limited. In order to maintain or increase quality many outsourcing firms employ quality management models such as Six Sigma, TQM and lean thinking. He adds that outsourcing increases productivity, quality services as well as substantially lowering the firm's and consumer costs. The ability to influence the quality of outsourced production or services depend on the consumers and producers.

The ability to influence the quality of the outsourced production/services depends on the relationship between the client and service provider. If not handled well the product quality suffers. In order to maintain high quality, it is important to employ quality management system. Outsourcing has contributed greatly to the enhancement of quality in organizations because this concept involves the process of concentration on core competencies, hence quality output (Robinovich et al, 1999)

Outsourcing leads to improved customer service in terms of efficient attendance of customer issues and faster document delivery to customers (Brown, 2007). Limited information is available on the effect of outsourcing on quality improvement on products and services in Kenya. Hence the need for this study.

\section{Critical review:-}

Although outsourcing is a bound with benefits to the organization there are several other disadvantages or constraints that companies must be aware of because they might affect their performance (Kendrick 2007) companies should therefore strive to minimize the potential effect these risks could bring into their business. It should also be noted that there may be other factors that determine the extent of success of outsourcing that may out of the control of the organization.

\section{Conclusion:-}

From the review, it is evident that outsourcing affects productivity, costs and quality and thus the performance of an organization. This has been reflected by the high response which favours the variables with regard to outsourcing and subsequently the organizations performance. It is noted that the following services are outsourced: cleaning services, software development, renovations, security and catering services. Outsourcing was also noted to lead to cost saving, receipt of quality goods and services, efficiency in the organization and competitive prices for the goods and services outsourced the said in the productivity of the K.I.A for example. Outsourcing was also noted to affect costs since it leads to reduced costs of spending, outsourced services were cheap to maintain and that the outsourced services are timely thus reducing the costs of spending. Outsourcing also affected quality of goods and services procured as it enabled procurement of up to standard and this in turn affected the performance of the organization.

\section{Recommendations:-}

Based on the review findings, the following recommendations apply:

\section{Improving on Outsourcing:-}

Based on this study it would be concluded that evaluation of the tenderers, monitoring of performance, transparency in bidding process, supervision of staff, the tendering process done by independent company and the auditing of the local purchase orders and vouchers for contracts had positive impact. This would improve the outsourcing process and therefore the performance of the organization. 


\section{Improving on Productivity:-}

The analysis did suggest that competitive bidding, use of tenders to select suppliers, personnel involvement in the outsourcing process, price analyses and creation of awareness among staff should be enhanced and taken seriously so that the staff should be able to look at outsourcing as accost cutting activity of the Institute and not as a way of taking over their jobs.

\section{Improving on costs:-}

The bulk buying, procurement of approved goods and services, hiring qualified personnel and evaluation of process to identify the best line of fit

\section{Improving on Quality:-}

The respondents suggested that there should be a clear policy that supports the current procurement Act within the Institute and the policy should be tied together with the Institute's outsourcing activities, before outsourcing, or putting open advertisement when requesting interested parties to bid for outsourcing services contracts, for the suppliers to buy and compete, giving specifications of outsourced services and goods, identification of the best brand in the market, and checks to ensure goods and services procured are of high quality.

\section{Suggestion for further research:-}

The study only focused on Kenya Institute of Administration. Further research should be done in the public sector and other organizations on the effect of outsourcing on the organizational performances. This will give a broader scope of the effects of outsourcing on organizational performances in the public sector

\section{References:-}

1. Abraham K. G. and Susan K. Taylor, 1996. "Firms" use of outside contractors: "Theory and evidence" Journal of Labour Economics, Vol. 14. Pp. 394-424.

2. Ashby (2002): Management and Profitability: Central review of the tasks and performance Vol. 19 pp. 23-26

3. Automatic Data Processing (2007). What is outsourcing? - www.adp.ca

4. Bhuyan, S., (2002). "Impact of Vertical Mergers on industry profitability: an empirical evaluation" Review of industrial Organization, Vol.20, pp 61-79.

5. Chpra, Sunil and Meindl, P.Supply Chain Management: Strategy, planning and operation

6. Corbett, M.F. (2004). The outsourcing Revolution: why it makes sense and how to do it right http://tools.ashbrige.org.uk

7. Elmuti. D (2003) The perceived impact of outsourcing and organizational performance. Mid-American Journal of business, fall 2003, vol. 18 No.2 - www.bsu.edu/mcobwin/majb

8. Emblton and Write: Measuring Performance in Public Sector and Non-profit Organizations. San Francisco, CA John W. and Sons Inc., 2003

9. Fixler and Siegel (1999) Management Information System: managing the digital firm in New Delhi: Pearsons Education Centre

10. Frayer (2000): The outsourcing- Pro and Cons in performance management: htt://tools.ashbringe.org.uk

11. Freenstra and Haston (1999): The International outsourcing and Productivity: Evidence from Great Britain (UK), the Journal of Economics and Finance

12. Görg, h and Harley (2004) International Outsourcing and productivity: Evidence from Irish electrical industry. The North American Journal of Economics and Finance.

13. Görg, Holger, Aoife H. and Eric S., 2004. "Outsourcing, foreign ownership, exporting and productivity: an empirical I nvestigation with plant level data" GEP Research paper 04/08, University of Nottingham

14. Kaplan R., and D. Norton (1996) Using the Balanced Scorecard as a Strategic Management System. Harvard Business Review (January-February): 75-85 Kendrick, C (2006) outsourcing issues - www.outsourcingweblog.com

15. Laudon and Laudon J.P.(2004), Management Information System: Managing the Digital firm. New Delhi: Pearson Education.

16. Lice C. Stewart and Julie C. (2003) The balanced Score Card-Beyond Reports and Rankings, Journal of Business Venturing and Advances in International Comparative Management New Jersy. Pearson Education, Inc., 2007

17. Njihia (2005): Outsourcing in public sectors: Empirical evaluation review of industrial organization Vol. 12, pp 5-8 
18. Poister, T.H. Measuring performance in public and non-profit organizations. San Francisco, CA: John W. \& Sons, Inc., 2003

19. Quinn, B.J. (2000), Outsourcing Innovation: The new engine of growth. Sloan Management Review 41 (14): 13-23

20. Rabinvichwindle, E; Windle, R. Dresner, M and Corsi, T. (1999): Outsourcing integrated logistics functions; an examination of industry practice. International Journal of physical distribution and logistics Management.

21. Robbins and Courtler (2003) Outsourcing in Public Sector, Ashford Color Press, Hants G. Britain

22. Russell, M. (2007) Outsourcing Guide-www.outsourcing-guided.com

23. Smith. T. (2000) Managing the Outsourcing Process. Credit and Financial Management Review, $4^{\text {th }}$ Quarter. Estate Investors (Aug.) Vol. 37:42-50

www.kia.ac.ke

www.wikipidia.com 